\title{
ESCREVER DO CORPO, O CORPO DA POESIA: CORPOREIDADES poéticas em Maria Teresa Horta
}

José Rosa dos SANTOS JUNIOR*

\section{RESUMo}

O presente artigo analisa as corporeidades poéticas que se forjam no âmbito da poética de Maria Teresa Horta e, em especial, na obra Palavras Secretas (2007). Dona de uma dicção comprometida e implicada com uma estética feminina e feminista, Maria Teresa Horta faz parte de uma linhagem de poetas contemporâneos que se debruçam sobre as questões mais genuínas que atravessam a problemática do gênero e toda a rede conceitual e metafórica que se desdobra a partir dessas questões. Fundamentam a nossa análise os pressupostos teóricos de Butler (2017), Perrot (2007), Beauvoir (1970), Tedeschi (2008), Louro (2007), dentre outros.

PALAVRAS-CHAVE: autoria feminina; corpo; poesia contemporânea.

Maria Teresa Horta nasceu em 20 de maio de 1937, na cidade de Lisboa e tem se consolidado como uma das vozes mais expoentes da poesia portuguesa contemporânea. A poética de Horta, não raro, se apresenta implicada com uma dicção e uma cartografia feminina e feminista, de inclinação erótica e que, em última instância, desestabiliza e tensiona determinadas textualidades (inclusive literárias), por plasmar poeticamente uma espécie de denúncia da repressão sexual que pesava simbólica e violentamente sobre a mulher portuguesa nos anos de 1960.

A literatura portuguesa, matiz e matriz - ainda que pela via da desconstrução - de tantas outras literaturas, não raro se colocou e reclamou para si, um lugar de destaque, na construção do imaginário português.

Professor de Língua Portuguesa e Literaturas do Instituto Federal de Educação, Ciência e a Tecnologia do Pará/IFPA, Marabá, Pará, Brasil.

E-mail: juliteratta@gmail.com Orcid: https://orcid.org/0000-0001-6411-4048 
Essa construção simbólica, mas também factual, se deu em um duplo contínuum literariamente producente: o artista bebia e tragava as histórias e os venenos do seu tempo, para daí engendrar o seu próprio antídoto: a obra literária. Antídoto, nesse contexto, altamente problemático, por reafirmar e exaltar a história portuguesa e os seus venenos, principalmente no que tange aos feitos da expansão ultramarina e as descobertas de terras e riquezas além-mar: remédio para a Coroa Portuguesa, veneno para os povos da África, América e Ásia.

Das urgências e emergências que a modernidade e a contemporaneidade portuguesa trouxeram para a pauta das discussões e para a ordem do dia, podemos citar a onda crescente do fascismo mundial, o machismo, o número cada vez mais alarmante de feminicídio que levou milhares de mulheres a protestar, nas ruas de Lisboa, no dia 14 de fevereiro de 2019, após o assassinato de 10 mulheres, desde o início do ano, índice mais alto da história do país, conforme Amato (2019).

De acordo com Amato (2019, on-line),

Descrições de cenas medievais e a exposição do machismo no Poder Judiciário Português ganharam as manchetes, quando um homem usou um bastão cravejado de pregos para espancar a mulher, com ajuda do amante da vítima. Um juiz do Tribunal da Relação do Porto minimizou a violência e jogou a culpa na mulher, classificada como "adúltera, dissimulada, falsa, hipócrita e desleal". Depois disso, o juiz foi apenas advertido no Conselho Superior da Magistratura.

A Associação de Mulheres Juristas de Portugal classificou como uma aberração, a decisão, em segunda instância, do juiz desembargador Neto de Moura, do Tribunal da Relação do Porto. O caso aconteceu em 2015 e a decisão, que chocou a opinião pública portuguesa, foi proferida em outubro de 2017. De acordo com Longo (2017), jornalista da Revista Fórum, a mulher havia se separado e foi vítima de uma emboscada armada pelo ex-marido e pelo amante, que a sequestraram e a agrediram. Ambos os homens foram condenados a mais de um ano de prisão, mas a pena foi suspensa em seguida. O Ministério Público português, então, recorreu 
para que a pena fosse aplicada e, em segunda instância, o juiz absolveu os agressores e culpabilizou a vítima usando como referência a Bíblia:

Ora, o adultério da mulher é um gravíssimo atentado à honra e dignidade do homem. Sociedades existem em que a mulher adúltera é alvo de lapidação até à morte. Na Bíblia, podemos ler que a mulher adúltera deve ser punida com a morte. Ainda não foi há muito tempo que a lei penal (Código Penal de 1886, artigo 372.0) punia com uma pena pouco mais que simbólica o homem que, achando sua mulher em adultério, nesse ato a matasse. (MOURA, $2017^{1}$ apud LONGO, 2017, p. 1).

Diante de uma decisão misógina, feminicida e medieva, em pleno século XXI, na Europa, é importante indagar a forma como a literatura portuguesa tem construído representações capazes de implodir simbolicamente as estruturas sociais calcadas nas alteridades sufocadas por uma pretensa ordem castradora de subjetividades e que perpetua a ideia, atrelada a uma mentalidade e a uma narrativa judaico-cristã, de que existe apenas um espaço reservado para a mulher: o da servidão e da subserviência.

Concordamos com Butler (2017, p. 8-9), quando a estudiosa e feminista, ao falar dos "problemas de mulher", afirma que "ser mulher é uma indisposição natural” e "por mais séria que seja a medicalização dos corpos das mulheres, o termo também é risível, e rir das categorias sérias é indispensável para o feminismo". Butler, como já afirmamos em um estudo anterior (SANTOS JUNIOR, 2019), ainda assevera que a fronteira e a superfície dos corpos são politicamente construídas e que se faz necessário romper as categorias de corpo, sexo, gênero e sexualidade, ocasionando sua ressignificação subversiva e sua proliferação para além da estrutura binária e do regime da heterossexualidade compulsória.

LONGO, Ivan. Juiz usa a bíblia para absolver homem que agrediu a esposa usando um bastão com pregos. Revista Fórum, São Paulo, 30 out. 2017. Disponível em: <https://oglobo.globo. $\mathrm{com} /$ sociedade/em-portugal-mulheres-convocam-protestos-contra-indice-recorde-de-feminicidio-no-pais-23451450>. Acesso em: 10 ago. 2019. 
É nesse cenário - que gesta e expõe as fraturas políticas, culturais e sociais necessárias e produtivas - que se ergue e nos interpela a poética de Maria Teresa Horta. Preocupada com as questões mais genuínas e constitutivas do ser mulher, a poesia de Horta plasma, de maneira subversiva e imperiosa, as problemáticas - ainda que por intermédio da analogia - do gênero, da sensualidade, do erotismo, do corpo, dos desejos e das paixões prenhes de odores, sabores e vertigens.

Indagada por Floriano Martins sobre os escândalos decorrentes da leitura de alguns dos seus livros, a poeta responde:

O escândalo de que falas só surge em 1971, quando da publicação de Minha Senhora de Mim. E é sobretudo um escândalo que parte do puritanismo, do machismo, do marialvismo, que então minava e destruía a sociedade portuguesa. Produto de uma mentalidade formada, moldada pelo Fascismo e pela igreja católica, portanto pela falta de liberdade, pelo moralismo, pela hipocrisia; uma sociedade onde as mulheres não tinham sequer direito a possuir uma sexualidade própria. Então, um livro como Minha Senhora de Mim, onde não só canto o corpo do homem amado e desejado, como claramente falo do meu próprio corpo e menciono o meu próprio desejo e prazer, só poderia escandalizar e ser proibido, como aliás aconteceu. (HORTA, 2007, p. 9). ${ }^{2}$

Consciente de seu papel de transgressão, irremediável, por meio da escritura literária e de todos os fatores socioculturais que interferem na construção e na recepção do construto poético, Horta construirá, ao longo de sua trajetória artística, que se reverbera em desconstruções, mas também em inserções políticas, uma série de poemas que reclamam a liberdade de expressão feminina. Essa liberdade de expressão, em primeira e em última instância, também está implicada com uma "liberdade plena" do corpo feminino e das ardências, do fogo e do desejo que o constitui.

2 Em entrevista intitulada $O$ corpo aceso da poesia de Maria Teresa Horta: conversa com Floriano Martins, concedida a Floriano Martins, em julho de 2007, e publicada, como uma espécie de prefácio, na obra Palavras Secretas (2007). 
Se o corpo físico desse eu lírico feminino se consome em gozos e em experiências eróticas vitais e fundamentais no conhecimento de si mesma, notamos que tais experimentações atravessam o campo do corpomaterialidade e se transformam no próprio corpo da poesia. No poema "O corpo, os corpos", vemos, já nos primeiros versos, um ensinamento: "é preciso dizer do corpo o corpo da poesia", ou seja, o corpo da poesia nada mais é, nesse caso específico, que a escritura corpórea de um "eu" atalhada pelas mais diversas experiências eróticas, que transbordam de si e encharcam de gozo o poema. Vejamos:

\section{O CORPO, OS CORPOS}

Dizer do corpo

o corpo da poesia

Os ombros

os seios

o ventre que sequestra

Entre as pernas fechadas

a vagina

com a sua longa boca entreaberta

Pensar do corpo

o corpo da poesia

Mais os dedos do que as mãos

sobre as arestas

Mais as fendas do que o liso

Mais a ruga

Mais a rusga das coxas

e das pernas

Depois vêm os dentes e a língua

a descer no trilho brando do umbigo 
Bebendo o sal

do suor da pele

e o fermento de um doce que não digo

Escrever do corpo

o corpo da poesia

Os pulsos tão febris

a nuca

e a garganta

O silêncio de uns olhos

que por certo queriam

ver bem mais longe do que o púbis deixa.

(HORTA, 2007, p. 113).

O poema "O corpo, os corpos" encena, desde o título, os motes que conduzirão o leitor pela arquitetura poemática: o corpo físico feminino que, atravessado pelas mais diversas experiências eróticas, se desdobra e engendra um corpo poético pleno de língua, de suor e de febre. É a partir de experimentações de uma corporeidade humana, que a corporeidade da poesia se construirá. E isso fica muito claro nos dois primeiros versos do poema: "dizer do corpo o corpo da poesia".

Fazer com que um corpo-mulher fale, a ponto de se transformar em um corpo-poesia, é atentar-se para as inúmeras reivindicações e demandas a que esse corpo está submetido, com o propósito de transformar ou de plasmar tais vivências, em inscrições políticas, mas igualmente estéticas. Se é imperioso dizer do corpo, o corpo da poesia, cabe-nos refletir de qual corpo e a qual corpo esse eu lírico se refere, e como esse corpo reelabora esses atravessamentos, transformando-os em transbordamentos poéticos, numa espécie de simbiose entre vida e arte.

Dessa forma, é necessário e producente que não nos esqueçamos que o corpo a que o poema se refere é um corpo feminino - que por si só, já encena e performatiza uma série de questões sociais, culturais e históricas a que o corpo da mulher esteve submetido ao longo dos 
séculos. Segundo Leite (2016), os nossos corpos são educados através de processos e pedagogias distintas: na família, na escola, nos ambientes e situações por onde transitamos e que vão nos atravessando enquanto experiência. Essas pedagogias, principalmente, as de cunho judaico-cristã, tecem um construto, radicado no simbólico e no discursivo, com vistas à construção de um "modelo de mulher".

De acordo com Tedeschi (2008), uma das instituições que mais se empenhou na construção de um "paradigma do feminino" foi a Igreja Católica. Para ele, a igreja criou dois protótipos de autorrepresentação da mulher na tradição cristã: "Eva pecadora" e "Maria Virtuosa”. Tais instâncias antagônicas são utilizadas, conforme o autor, pelo cristianismo para representar, mas também violentar, todo o universo feminino.

Ao refletir acerca dos espaços sociais das mulheres, Tedeschi (2008, p.101) afirma que há "lugares e funções que se constroem pelo casamento e reforçam o ideal de lar e de maternidade - como papeis historicamente construídos e legitimados pela moral cristã” e que, durante muito tempo, definiram a identidade feminina e as limitaram ao espaço privado. No entanto, o poema de Horta desestabiliza e rasura esse ideário de mulher confinada no espaço reservado, ao trazer para o corpo do poema, a representação do corpo de uma mulher.

Essa mulher-poema, agora ofertada a uma coletividade, molda uma arquitetura poemática plena de curvas, de sensualidade e de erotismo, que se revela por meio da linguagem e de sua sintaxe. Trata-se de um poema com ombros, seios, ventre e que ostenta, entre as pernas fechadas, "a vagina com a sua longa boca entreaberta". Vemos, aqui, uma fratura irreversível dos padrões canônicos literários FaloFonoEtnoLogocêntricos. A poesia produzida por machos-brancos-heteros, e que se quer modelar, encontra, na poética de Horta, um contraponto crítico e uma voz feminina orgulhosa e senhora de si e do seu corpo e que desvela e revela, ao público, uma corporeidade poética, altamente comprometida e afetada, pela representação de um corpo de mulher.

O eu lírico, ainda, nos ensina mais: é preciso "pensar do corpo o corpo da poesia”. Aprendemos, com o poema, que é a partir do corpo que 
se diz e que se pensa a poesia. É como se a escritura poética de autoria feminina só fosse possível a partir de uma implicação afetiva, mas também política, com aquilo que a mulher tem de mais temido e de mais poderoso: o seu corpo, que também é marca, que também é signo, que também é trauma, que também é discurso e que também é resistência.

Se o eu lírico nos chama a atenção e nos diz que é preciso "dizer do corpo o corpo da poesia" e "pensar do corpo o corpo da poesia", o poema ainda assevera que é necessário "escrever do corpo o corpo da poesia", com nuca, garganta e pulsos febris. A febre e o calor do fogo que incendeia o corpo dos amantes, no último terceto do poema, são contrastados com "o silêncio de uns olhos" - e, aqui, nos interpela a utilização do artigo indefinido - porque indefine, por um lado, o dono dos olhos e, por outro, a própria operação sinestésica, uma vez que o modo como a imagem é construída pode ser um indicativo da presença de uma operação metafórica.

No entanto, esses olhos - que não são "os", mas "uns" - silenciosos ou silenciados pela potência do encontro com o corpo, agora transformado em poesia, e que, segundo o eu lírico, estão desejosos de "ver bem mais longe o púbis deixa”. Nesse momento, se confundem e se embaralham, no nosso entender, duas instâncias bastante produtivas, se quisermos aprofundar as relações insinuadas pelo eu lírico: o amante e o leitor. Decerto que esses olhos gulosos e desejantes, que aspiram ver o que, momentaneamente, não pode ser visto, para além da utilização do indefinido, como já sinalizamos, apontam, em primeira instância, para os olhos daquele que toca o corpo, mas também aponta para o leitor, "impedido" de ver para além daquilo que o corpo do poema revela.

Convém ressaltar que, apesar do poema plasmar e ser um corpo que se mostra, que se revela e que é tocado, é notória a indeterminação de gênero do agente. A possibilidade interpretativa que nos interpela é a de um corpo que se mostra no momento que se toca. Trata-se, portanto, de uma ação de autoconhecimento que se constrói na masturbação feminina, evidenciando mais um gesto de transgressão e de ruptura irreversíveis de valores calcados numa lógica patriarcal, machista e misógina que 
fundam grande parte da sociedade ocidental, mas que permitiram, ainda que clandestinamente, em um primeiro momento, a insurgência de uma variedade de corpos indóceis, como é o caso do corpo-poema que acabamos de analisar.

Outro "arrombamento" que se faz presente no poema, diz respeito ao fato de tematizar aquilo que, historicamente, foi reservado - pelas estruturas patriarcais - ao campo do não dito. Louro (2007) afirma que a sexualidade feminina sempre foi um assunto privado, alguma coisa da qual se poderia falar tão somente com alguma pessoa muito íntima e, de preferência, de forma reservada. "A sexualidade - o sexo, como se dizia - parecia não ter nenhuma dimensão social; era um assunto pessoal e particular que, eventualmente, se confidenciava a uma amiga próxima” (LOURO, 2007, p. 4). No nosso caso, Maria Teresa Horta nos elege como "a amiga próxima”, o que resultou, no contexto português, na segunda metade do século XX, em um choque no sujeito leitor.

Esse choque é resultado de um trabalho de desestabilização, por meio da atividade poética, das normas, das leis, das regulações e dos dispositivos de controle da sociedade patriarcal, que, de acordo com Perrot (2007), fizeram com que os corpos femininos fossem subjugados, dominados e violentados das mais diversas formas. Perrot (2007) afirma, ainda que, durante muito tempo, as mulheres foram objeto de um relato histórico que as relegou ao silêncio e à invisibilidade: ao mesmo tempo que são excessivamente descritas, representadas e imaginadas, são também silenciadas.

No poema a seguir, notoriamente metalinguístico, metapoético e autorreflexivo, o eu lírico constrói uma série de sugestividades, moduladas por uma atmosfera poética, mas também idílica, amorosa, erótica. Aqui, o poema se assemelha, ou engendra, ou forja, ou se aloja em um lugar do ser amado, que chega de longe trazendo boas novas. Vejamos:

\section{POEMA}

Deixo que venha se aproxime ao de leve 
pé ante pé até ao meu ouvido

Enquanto no peito o coração

estremece

e se apressa no sangue enfebrecido

Primeiro a floresta e em seguida

o bosque

mais bruma do que neve no tecido

Do poema que cresce e o papel absorve

verso a verso primeiro

em cada desabrigo

Toca então a torpeza e agacha-se

sagaz

um lobo faminto e recolhido

Ele trepa de manso e logo tão voraz

Que da luz é a noz

e depois o ruído

Toma ágil o caminho

e em seguida o atalho

corre em alcateia ou fugindo sozinho

Na calada da noite desloca-se e traz

consigo o luar

com vestido de arminho

Sinto-o quando chega no arrepio

da pele, na vertigem selada

do pulso recolhido

À medida que escrevo

e o entorno no sonho

o dispo sem pressa e o deito comigo.

(HORTA, 2007, p. 168). 
O título do poema já aponta para o caráter metapoético, o qual nos referimos anteriormente: "Poema”. À primeira vista, metonimicamente, pode se vislumbrar, no horizonte de expectativas do leitor, que o poema se debruça e tematiza as questões da criação poética e da escrita criativa, do ponto de vista da autoria feminina. Já na primeira estrofe, se percebe a tentativa de aproximar a criação literária com uma espécie de possessão. O poema se utiliza das estratégias de aproximação do eu lírico e parece instituir ou até mesmo encenar ou sugerir, a temática da inspiração e do poeta como um sujeito inspirado.

É interessante notar o movimento coreográfico que o poema constrói: ele chega e se aproxima de leve, pé ante pé, do ouvido do eu lírico. No entanto, apreende-se um outro movimento, já na primeira palavra poemática: "Deixo", que implica no consentimento da ação do poema sobre o eu poemático. $\mathrm{O}$ efeito e o afetamento lírico - porque acreditamos que se trata de uma corporeidade afetada pelos ditames da poesia, mas afetada porque "deixa”, como a própria voz lírica faz questão de dizer -, só é possível porque há um sujeito disposto animicamente e dentro dos mesmos climas afetivos instaurados pela presença do poético.

A chegada do poema desestabiliza o corpo feminino: o coração estremece e se apressa no sangue enfebrecido, logo o eu lírico não se encontra imune às investidas do literário. A terceira estrofe, envolta em uma operação metafórica, revela o trajeto percorrido até a chegada da "luz". Primeiro, se adentra na densa floresta, plena de sinestesias e que termina por desorientar aquele que a adentra: sensações, cheiros, gostos, palavras, tudo isso concorre para a construção dessa floresta de palavras que permite, aos que cruzarem, o encontro com o bosque.

Chegar ao bosque não é uma garantia de "tranquilidade", afinal é o bosque quem confere "mais bruma do que neve ao tecido". Esse tecido-poema, envolto nas brumas do bosque, ora vela, ora desvela, como toda manifestação lírica por excelência que, por ser linguagem, encobre-revelando e revela-encobrindo. $\mathrm{O}$ poema não encena uma frieza, um encharcamento, visto que não se ergue em meio à neve, mas é 
nebulosidade, nevoeiro, embaralha a visão, até que cresça verso a verso e se mostre desabrigado e absorto sobre a materialidade do papel.

A construção imagética, a que o eu lírico se propõe e realiza, revela bastante acerca dos bastidores da escrita criativa. Escrever e, mais precisamente, plasmar o poético é fazer com que a poesia toque e adentre no que há de mais torpe e vil na existência humana em todas as suas incongruências e limitações. Há, aqui, uma tentativa de reatualizar o pensamento platônico e a velha divisão entre o mundo das ideias e o mundo das cópias ou dos simulacros, sendo a poesia/inspiração poética a representante daquele mundo e o poema, deste.

Trata-se de um poema que, ao ser recolhido, se mostra como um lobo faminto. Esse lobo-poema que, ora corre em alcateia, ora foge sozinho, ao chegar, por meio de caminhos e atalhos, segundo o eu lírico, trepa de manso, mas logo se mostra voraz. Como já dito anteriormente, se apresenta aqui uma espécie de possessão da obra sobre o artista que, ainda que permita a aproximação, como bem demarcado no início do poema, se encontra disponível ou aberto às investidas do poético.

No entanto, o poema que, em primeira instância, se ergue e interpela o eu lírico, como um lobo faminto e voraz, se vale de estratégias de conquista desse corpo-mulher: agora já apaziguada a luta e o embate, e já deitado ao lado da presa, levanta-se na calada da noite e traz consigo o luar com vestido de arminho. Imagem mais poética não há. A conquista desse corpo, agora território do poético, se dá por via de protocolos e de sinalizações. É o próprio eu lírico quem nos diz "Sinto-o quando chega no arrepio da pele, na vertigem selada do pulso recolhido”.

Assim, podemos notar as reverberações e os efeitos da chegada do poético na materialidade do corpo feminino que se confunde com o corpo do poema, pois ambos apresentam uma ambivalência fundamental: ao mesmo tempo que são construtos materiais, são, igualmente, construções discursivas forjadas pela linguagem, pela cultura e pelo "tornar-se", como bem advertiu Beauvoir (1960).

A última estrofe do poema tece, mais uma vez, uma atmosfera amorosa, idílica e comprometida com as reflexões metapoéticas que já 
havíamos sinalizado no início de nossa análise. A empreitada do eu lírico, nesse poema, mas, também, em outros poemas da obra de Maria Teresa Horta, é erguer uma autorreflexão acerca do fazer poético, mas, agora, a partir do ponto de vista de um corpo, de uma autoria e de uma dicção feminina que à medida que escreve e entorna o poema em um clima onírico, o despe sem pressa e o deita consigo.

$\mathrm{O}$ ato de despir e de fazer com que o poema deite em seu leito faz com que o eu poemático adentre o reino das palavras pagãs, como veremos no poema abaixo:

\section{AS PALAVRAS PAGÃS}

É o fogo cinco vezes

na garganta

é o grito mais cansado

de se ouvir

São as unhas no suor

mais brando

o mar o ventre

ainda por abrir

São as palavras

que se repetem cedo

e uma a uma

mordidas e sugadas

São as palavras usadas

por inteiro

o fruto o leite

depois a madrugada

É o flanco do vento

o vinco da manhã 
o calor que sobe em sua

estrada

É a cal das coisas mais

pagãs

o fruto o leite

depois a madrugada.

(HORTA, 2007, p. 88).

O poema "As palavras pagãs" mais uma vez se debruça sobre as questões orgânicas do fazer literário. Aqui, se percebe a tentativa de dar conta da representação de uma humanidade que se mostra por meio de vocábulos ainda "não batizados" ou que se encontram comprometidos com vários deuses. A adjetivação que se atribui às palavras aponta para uma desconstrução do ideário religioso, de cunho judaico-cristão, pois, segundo os tais preceitos, os pagãos são considerados heréticos, pois interrogam e não confiam nas Sagradas Escrituras e nos demais dogmas pregados pelos ensinamentos cristãos.

A partir do título, o leitor já consegue (ou não) estabelecer um horizonte de expectativas acerca da questão temática que atravessará o poema: da implicação amorosa entre a mortal e o imortal, só pode ter, como efeito, uma relação pagã que se mostra como um fogo na garganta, não qualquer fogo, mas um fogo elevado à quinta potência. $\mathrm{O}$ elemento fogo é comumente associado à purificação, à vida, ao sol, mas também aos desejos carnais e sexuais, não é à toa que, na Idade Média, os corpos indóceis eram condenados à fogueira, como forma de consumição e expiação dos "pecados".

As palavras pagãs, que brotam no fluxo do poema, são fogo, mas também são gritos - cansado de se ouvir. Esse grito, agora denunciado pelo texto poético, é um brado coletivo e uma marca inexorável da existência das mulheres, mas também dos negros, dos índios, dos homossexuais, dos moradores das favelas, das margens e das periferias. Por outro lado, dadas as referências e as pistas textuais, esse grito/gemido/sussurro parece apontar para o êxtase, para o experimento do gozo corporal e poético.

As palavras pagãs compreendem, ainda, as unhas no suor, o mar e o ventre e revelam essa íntima relação entre a palavra poética e o corpo, 
poeticamente grafado. $\mathrm{O}$ eu lírico assevera que os vocábulos pagãos que inundam o poema são aqueles que repetem logo cedo, são vocábulos mordidos e sugados - Boca? Seios? Lábios? Pescoço? Pênis? Vagina? Para serem pagãs, as palavras precisam ser usadas por inteiro, nos alerta a voz lírica.

$\mathrm{O}$ verbo pagão nos permite experimentar o fruto, o leite e as madrugadas, mas é, igualmente, tudo isso. É o flanco do vento, é o vinco da manhã, é o calor que sobe na estrada, ou seja, ele habita e circunda nas sutilezas do cotidiano, nas coisas mais simples e corriqueiras do dia a dia. A palavra pagã é rasura, é desconstrução, é tensão, por isso é tão comprometida com o universo feminino que, desde sempre, esteve ligado às zonas mais fronteiriças, mas também insubmissas, da existência humana, uma vez que tais palavras sempre estiveram nas pautas e na ordem do dia do universo masculino.

Se valer de tal repertório e de tal arsenal linguístico, calcados na representação de uma realidade que se constrói, nos meandros, nas encostas e nas beiradas é, por si só, um ato de rebeldia e de resistência. Ser “a cal das coisas mais pagãs" é, de certa forma, resguardar a coisa em si e revelar sua materialidade, por meio do trabalho com a linguagem, que faz com que a coisa dita já não seja a coisa experimentada, vivenciada, mas a coisa narrativizada e, mais especificamente, poetizada.

Ser a cal das coisas confere, à palavra, como já afirmamos anteriormente, um papel de destaque na revelação e no resguardo dos eventos e dos fenômenos que atravessam o cosmos e que afetam esse corpo de mulher. Não é à toa que, para Heidegger (2005), a linguagem é a morada do ser. E ainda, segundo Heidegger, a arte é uma consagração e um abrigo, por onde o real dispensa ao homem o seu brilho até então escondido, para que, numa tal claridade, possa ver, de maneira mais pura, e ouvir, mais distintamente, o que fala à sua essência.

Segundo Nunes (1992), mais diretamente do que qualquer outra arte, a poesia participa, pela palavra, que constitui a sua matéria, do trabalho preliminar e mais primitivo do pensamento, como obra da linguagem. A poesia é o limiar da experiência artística em geral por ser, antes de tudo, o limiar da experiência pensante: ponto de irrupção do ser na linguagem, mas também de interseção da linguagem com o pensamento. Heidegger (2005) nos diz que todas as outras artes só se produzem quando já se 
produziu a clareira pela "poesia primordial" da linguagem. A língua é a poesia originária em que um povo poetiza o ser.

De acordo com Nunes (1992, p. 275):

A poesia celebra e comemora. Celebração do sagrado, que atende ao seu apelo, e comemoração das divindades ausentes, a poesia manifesta o páthos do sofrimento, mas também da alegria e da esperança - que abre através da palavra nomeadora. A palavra que funda, celebrando e recordando, é o canto no jogo da linguagem, que separa o pensamento, como pensamento do ser, da poesia como nomeação das coisas.

A palavra poética nomeadora que, segundo Nunes, celebra o sagrado, em Maria Teresa Horta é, também, a celebração das coisas profanas, das palavras profanas, afinal, as experiências corporais femininas, uma vez representadas, só podem estar na fluidez e na potência da desconstrução e do profano. Esse corpo que é materialidade, mas que, também, ou antes de tudo, é discursividade, é construção linguística, é uma obra da linguagem, produz a clareira sobre as questões genuínas acerca da construção histórico-sócio-cultural do ser mulher e revela uma identidade problemática e discursivamente constituída.

Dessa forma, se a linguagem, não raro, sempre esteve implicada e à disposição de regimes calcados na masculinidade-branca-europeia, em Horta, é por meio dessa mesma linguagem/estrutura de poder, que produz e reprime o sujeito do feminismo, que a poeta busca a sua emancipação. Como Butler (2017), acreditamos que a formação do sujeito ocorre no interior de um campo de poder e as estruturas jurídicas da linguagem e da política constituem esse campo contemporâneo do poder; e, consequentemente, não há posição fora desse campo, mas somente uma genealogia crítica de suas práticas de legitimação.

WritiNG THE BODY, THE BODY OF POETRY: POETIC BODIES IN MARIA TERESA HORTA

\section{Abstract}

This article aims to analyze the poetic corporeities that are forged in the context of Maria Teresa Horta's poetics and, in particular, in the work Secret Words 
(2007). Owned by a compromised and implicated diction with a feminine and feminist aesthetics, Maria Teresa Horta is part of a lineage of contemporary poets addressing the most genuine issues that cross gender issues and the entire conceptual and metaphorical network that unfolds itself. from these questions. We base our analysis on the theoretical assumptions of Butler (2017), Perrot (2007), Beauvoir (1970), Tedeschi (2008), Louro (2007), among others.

KEYWORDS: female authorship; body; contemporary poetry.

ESCRIBIR DEL CUERPO, EL CUERPO DE LA POESÍA: CUERPOS POÉTICOS EN Maria Teresa Horta

\section{RESUMEN}

Este artículo tiene como objetivo analizar las corporealidades poéticas que se forjan en el contexto de la poética de María Teresa Horta y, en particular, en la obra Palabras Secretas (2007). Dueña de un compromiso comprometido e implicado con una estética femenina y feminista, Maria Teresa Horta es parte de un linaje de poetas contemporáneos que abordan los problemas más genuinos que cruzan la problemática del género y toda la red conceptual y metafórica que se desarrolla. de estas preguntas. Basamos nuestro análisis en los supuestos teóricos de Butler (2017), Perrot (2007), Beauvoir (1970), Tedeschi (2008), Louro (2007), entre otros.

PAlabras ClaVe: autoría femenina; cuerpo; poesía contemporánea.

\section{REFERÊNCIAS}

AMATO, Gian. Em Portugal, mulheres convocam protestos contra índice recorde de feminicídio no país. $O$ Globo, São Paulo, 14 fev. 2019. Disponível em: <https://oglobo.globo.com/sociedade/em-portugal-mulheres-convocamprotestos-contra-indice-recorde-de-feminicidio-no-pais-23451450>. Acesso em: 10 ago. 2019.

BEAUVOIR, Simone. O segundo sexo: fatos e mitos. São Paulo: Difusão Europeia do Livro, 1960. 
BUTLER, Judith. Problemas de gênero: feminismo e subversão da identidade. Tradução Renato Aguiar. Rio de Janeiro: Civilização Brasileira, 2017.

HORTA, Maria Teresa. Palavras secretas. São Paulo: Escrituras Editora, 2007.

LEITE, Fernanda Capibaribe. Corpos em cena e trânsito: sujeitos em devir na filmografia de Claudia Priscilla. In: COLLING, Leandro (Org.). Dissidências sexuais e de gênero. Salvador: EDUFBA, 2016.

LONGO, Ivan. Juiz usa a bíblia para absolver homem que agrediu a esposa usando um bastão com pregos. Revista Fórum, São Paulo, 30 out. 2017. Disponível em: < https://revistaforum.com.br/global/juiz-usa-biblia-para-absolver-homem-queagrediu-esposa-usando-um-bastao-com-pregos >. Acesso em: 10 ago. 2019.

LOURO, Guacira Lopes (Org.). O corpo educado: pedagogias da sexualidade. Tradução Tomaz Tadeu da Silva. Belo Horizonte: Autêntica, 2007.

HEIDEGGER, Martin. O ser e o tempo. Tradução Márcia Sá Cavalcante Schuback. Rio de Janeiro: Editora Vozes, 2005.

MARTINS, Floriano. O corpo aceso da poesia de Maria Teresa Horta: conversa com Floriano Martins. In: HORTA, Maria Teresa. Palavras secretas. São Paulo: Escrituras Editora, 2007.

NUNES, Benedito. Passagem para o poético: filosofia e poesia em Heidegger. São Paulo: Ática, 1992.

PERROT, Michelle. Minha história das mulheres. São Paulo: Editora Contexto, 2007.

SANTOS JUNIOR, José Rosa dos. A mulher sábia edifica a sua casa, a louca a desmorona: imagens de mulher na poesia de Renailda Cazumbá. Revista Brasileira de Literatura Comparada, v. 21, n. 38, p. 118-127, 2019.

TEDESCHI, Losandro Antonio. A história das mulheres e as representações do feminino na história. Campinas: Curt Nimuendajú, 2008.

Submetido em 15 de abril de 2020

Aceito em 11 de agosto de 2020

Publicado em 30 de setembro de 2020 